\title{
Ceramic membranes for ammonia recovery
}

\author{
Y.C. van Delft, D.F. Meyer, P.P.A.C. Pex \\ O. Camus, S. Perera, B. Crittenden (Univ. of Bath) \\ I. Kumakiri, S. Miachon, J.A. Dalmon (CNRS) \\ S. Tennison (MAST Carbon Ltd.) \\ P. Chanaud (Pall-Exekia) \\ E. Groensmit (Kemira GrowHow SA)
}

Published in AIChE Journal, Vol. 52, No. 6, June 2006, 2055-2065 


\title{
Ceramic Membranes for Ammonia Recovery
}

\author{
Olivier Camus, Semali Perera, and Barry Crittenden \\ Dept. of Chemical Engineering, University of Bath, Bath, BA2 7AY, U.K. \\ Yvonne C. van Delft, Dick F. Meyer, and Paul P. A. C. Pex \\ Energy Research Centre of the Netherlands ECN, Westerduinweg 3, P.O. Box 1, 1755 ZG Petten, The Netherlands
}

Izumi Kumakiri, Sylvain Miachon, and Jean-Alain Dalmon

CNRS-Institut de Recherches sur la Catalyse 2, av. A. Einstein, 69626 Villeurbanne, France

Steve Tennison

MAST Carbon, Ltd., Henley Park, Guildford, Surrey, GU3 2AF U.K.

Philippe Chanaud

Pall-Exekia, BP1, Usine a Bazet, France

Ernest Groensmit

Kemira GrowHow SA/NV, Avenue Einstein 11, B-1300 Wavre Belgium

Wil Nobel

Continental Engineers BV, Rustenburg 114, 1506 AZ Zaandam, The Netherlands

DOI 10.1002/aic. 10800

Published online March 1, 2006 in Wiley InterScience (www.interscience.wiley.com).

An extensive screening program has been performed to find a suitable membrane configuration and operating conditions for the effective recovery of ammonia from the syngas loop. All the experiments have been performed at steady state. MFI zeolite membranes in tubular and multi-channel fiber configurations have been tested along with tubular silica membranes. At $80^{\circ} \mathrm{C}$, a high ammonia permeance $\left(2.1 \times 10^{-7} \mathrm{~mol} \cdot \mathrm{m}^{-2} \cdot \mathrm{s}^{-1} \cdot \mathrm{Pa}^{-1}\right)$, and a selectivity of about 10 were found with the tubular zeolite membrane, whereas for the silica membrane an even higher ammonia permeance was measured $\left(7.6 \times 10^{-7} \mathrm{~mol}^{-\mathrm{m}^{-2}} \cdot \mathrm{s}^{-1} \cdot \mathrm{Pa}^{-1}\right)$ with a selectivity of about 7. For both silica and zeolite membranes, the selectivity was found to increase with increasing temperature up to $80^{\circ} \mathrm{C}$. This is a combined effect of weaker adsorption of ammonia and increased diffusion at higher temperature. The results have been modeled using both the well-mixed reactor and the log mean pressure difference approaches. To overcome their limitations in addressing changes in feed concentration along the membrane surface, a segmental model has been used to obtain suitable operating conditions and membrane areas required for an industrial application. (c) 2006 American Institute of Chemical Engineers AIChE J, 52: 2055-2065, 2006

Key words: ceramic membranes, ammonia separation, gas separation, zeolite, silica, simulation

\section{Introduction}

It is generally accepted that membrane processes not only offer significant energy savings compared to more conven-

\footnotetext{
Correspondence concerning this article should be addressed to $\mathrm{O}$. Camus at
} o.camus@bath.ac.uk.

(C) 2006 American Institute of Chemical Engineers tional processes ${ }^{1,2}$ (for example, distillation, absorption, and so on), but also reduce the raw material inputs such that they do not require large inventories of hazardous chemicals. The use of membranes in separation processes has grown dramatically over the last 10 years, with an annual growth rate of around $10 \%$. However, the majority of this growth has been in liquid phase applications using polymeric membranes. Despite their costs, increasing usage of microporous ceramic membranes is 
now being seen primarily because of their excellent thermal and mechanical stability properties. Zeolite and silica membranes are important classes of microporous membranes since they are capable of separating compounds by a combination of molecular sieving, selective adsorption, and differences in diffusion rates. ${ }^{3-5}$

There has been much research over the last decade into the preparation of defect-free microporous ceramic membranes. For example, Hyun et al. ${ }^{6}$ reported that a pressurized-coating method followed by hydrothermal treatment gave a ZSM-5 composite membrane effective for carbon dioxide separation, providing a carbon dioxide/nitrogen separation factor of 9.0 at room-temperature for an equimolar binary mixture. They pointed to the simplicity and low energy needs of membranes as advantages in the reduction of carbon dioxide emissions, and gave a brief review of the use of ZSM-5 membranes for carbon dioxide separation. An existing application of zeolite membranes in carbon dioxide emission control is in the water-gas shift reaction where selectivities between 15 and 40 have been reported. ${ }^{7}$ Other $\mathrm{CO}_{2}$ applications include its recovery from combustion gases. ${ }^{8}$ Additionally, MFI type zeolite membranes of different morphologies prepared by hydrothermal synthesis on composite alumina support tubes gave an n-butane/isobutane permselectivity of 1.5 to 12 at $100^{\circ} \mathrm{C} .{ }^{9}$ Gavalas et al. reported several techniques to prepare ZSM-5 membranes on various supports. In one study ${ }^{10}$ they prepared these zeolite membranes using a TPA-free gel, while in another work they treated a ZSM-5 membrane by coking deposition to reduce micro-defects. ${ }^{11}$

Zeolite membranes reported in the literature are stable with respect to temperature and pressure, but contaminant species can significantly affect their permeation properties. An important requirement of any membrane to be used industrially is a high permeability, which increases the productivity, combined with a high selectivity. However, there is a major technical challenge in the development of supported true microporous membranes: large surface area defect-free membranes are technically very difficult to make, as very thin layers readily present defects (cracks). Our research group has concentrated on the routes of using single and multichannel tubes combined with new ideas for zeolite growth (the pore plugging approach) that can reduce both the cost and the complexity of the system.

Similar to the zeolites, silica membranes have been known for over a decade. ${ }^{12}$ Currently, microporous silica membranes show good potential for separation, especially in terms of their separation efficiency. ${ }^{13,14}$ However, the performance of these membranes deteriorate in the presence of water due to the hydrophilic nature of the silica surface. ${ }^{15}$ By incorporating methyl groups silica membranes with a pore diameter of 0.5 $\mathrm{nm}$ have been prepared by De Vos et al. ${ }^{16}$, and these membranes are shown to be slightly less hydrophilic than pure silica membranes. They prepared these membranes by repeated dip coating of supported $\gamma$-alumina membranes in a silica-sol solution, followed by drying and calcination. Campaniello et al. ${ }^{17}$ showed that by the incorporation of methyl groups in microporous silica it was possible to enhance considerably the service time in the dehydration of a butanol-water mixture. In order to examine the performance of this methylated silica membrane in ammonia separation we have prepared several batches of tubular methylated silica membranes according to recipes reported by Campaniello et al. ${ }^{17}$. In this study, the performance of new zeolite and silica membranes have been compared in terms of their permeation and separation factors.

Another factor limiting the development and use of microporous ceramic membranes is the problem associated with modeling their performance. In this research, two basic engineering models have been used initially for data analysis. The first considers the membrane, as a well-mixed reactor, while the second uses a log-mean pressure difference (LMPD) approach. In order to overcome their limitations, a third model has been used based on a series of well-mixed chambers, such that the concentration gradient along a high-flux membrane can properly be accounted for.

Modeling of gas permeation is currently capable of providing qualitative or semiquantitative information on membrane behavior, certainly for some of the more frequently studied systems. The method has been found to be useful for identifying desirable operating regimes. Kerkhof ${ }^{18}$ describes the Maxwell-Stefan approach of Krishna and van den Broeke ${ }^{19}$ as the best theoretical description of transport through membranes, such as silicalite on stainless steel supports. The work of Krishna and van den Broeke ${ }^{19}$ provides a numerical solution for transport across the zeolite membrane. In contrast, Kerkhof ${ }^{18}$ presents an analytical solution proposed for the prediction of selectivity from single-component data and for experimental data analysis. Marriott et al. ${ }^{20}$ developed a comprehensive model for gas separation considering mass and momentum balances on both sides of the membrane. The momentum balances are solved to yield the pressure profile, and the mass balance to yield the concentration profile along the membrane length.

In this study, the steady-state permeation behavior of an ammonia/hydrogen/nitrogen mixture with three membranes is presented: (1) tubular MFI-type zeolite on a ceramic alumina support, and (2) multichannel fiber MFI-type zeolite on a ceramic alumina support; and a tubular microporous silica. Simulations of experimental results for a range of operating conditions, including high-pressures that are used in industrial ammonia production, have been performed. The best configuration and operating conditions for effective ammonia separation are discussed. The simulation model also predicts the exit compositions and membrane surface area requirements for given industrial operating conditions.

\section{Membrane Development Zeolite membranes}

Two types of supports have been used to synthesize the zeolite membranes: tubes and multichannel fibers both made of alumina. The ceramic tubes, Membralox T1-7021 provided by Pall-Exekia, are composed of three layers of $\alpha$-alumina. These layers of $12 \mu \mathrm{m}, 0.8 \mu \mathrm{m}$, and $0.2 \mu \mathrm{m}$ pore dia. have respective thicknesses of approximately 1,500, 30 and $15 \mu \mathrm{m}$ (see Figure 1). The precursor of the zeolite was obtained by mixing silica (Aerosil Degussa 380) and a template (TPAOH). After a threeday aging period, the precursor was placed with the porous tube in an autoclave fitted with a PTFE insert. The hydrothermal synthesis was performed at $170^{\circ} \mathrm{C}$ for 3 days, and then the membrane was calcined at $500^{\circ} \mathrm{C}$ under a flow of air. Before use, the zeolite membrane tube $(150 \mathrm{~mm}$ length, $7 \mathrm{~mm}$ i.d., and $10 \mathrm{~mm}$ o.d.) was pretreated overnight at $100^{\circ} \mathrm{C}$ in flowing nitrogen to remove any adsorbed molecules from its pores. A 


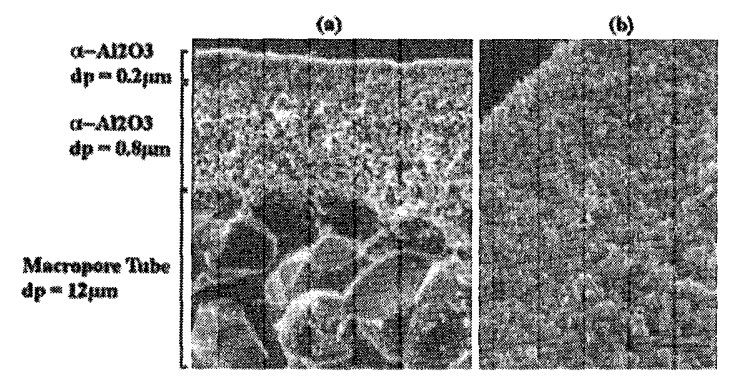

Figure 1. (a) Cross section of tubular membrane support structure, and (b) scanning electron microscopy (SEM) of the zeolite imbedded inner layer of the support.

detailed description of the composite membrane preparation, including the silica/TPAOH ratio, and its characterization can be found elsewhere. ${ }^{22,23}$ The zeolite selective layer is located in the inner part of the $0.2 \mu \mathrm{m}$ pore dia. support, and it is approximately 5 to $15 \mu \mathrm{m}$ thick.

With this pore plugging system, it was found to be relatively easy to obtain a continuous flawless zeolite layer. Furthermore, thermal cycling and occasional shocks are less likely to damage the membrane moiety when this is incorporated within the support than when it is laid down on its exterior surface. However, due to its low bursting pressure, this configuration is not suitable to be used in high-pressure industrial applications, such as the ammonia process, which requires a differential pressure of at least 100 bar. Consequently, the use of multichannel fibers as supports for the new membrane was considered as well. These new supports, developed by Pall-Exekia, ${ }^{24,25}$ are $250 \mathrm{~mm}$ in length, $5 \mathrm{~mm}$ o.d., with 7 internal channels of $0.8 \mathrm{~mm}$ in diameter, and they have a narrow pore size distribution of around $0.2 \mu \mathrm{m}$. The membrane synthesis is similar to that for the tube but with the addition of PTFE inserts in the channels to avoid any blocking due to zeolite growth.

\section{Silica membranes}

Several batches of tubular silica membranes have been prepared according to the recipe given by Campaniello et al. ${ }^{17}$. They have been made in a batch process, with a maximum of 12 tubes of $1 \mathrm{~m}$ length each time. The alumina substrate of the tubes was first coated on the outside with porous intermediate layers in order to overcome the surface roughness. A polymeric silica sol was made and coated on top of the intermediate layer ${ }^{26}$ and calcined at $400^{\circ} \mathrm{C}$ in air. Using this procedure, it was possible to prepare membranes with a pore size of around $0.5 \mathrm{~nm}$. These silica membranes can be optimized for a number of applications by modifying the silica sol or the calcination procedure. The separation layer of these membranes consists of a very thin $(<200 \mathrm{~nm})$ hydrophilic amorphous silica film on (a)
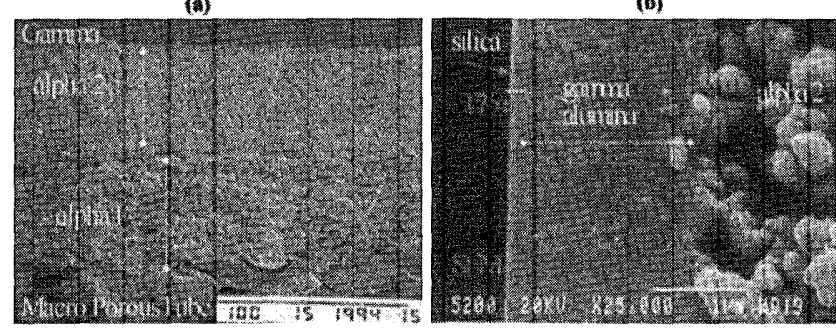

Figure 2. (a) SEM of support indicating three layers in a silica membrane, and (b) highly selective silica membrane layer.

the outside of a multilayer alumina support tube as shown in Figure 2.

The silica membrane tubes used in the test programme are cut to $100 \mathrm{~mm}$ length and have an i.d. of $8 \mathrm{~mm}$ and o.d. of 14 $\mathrm{mm}$. Some of the properties of the support and membrane layers are given in Table 1.

To increase the ammonia permeance, the silica structures were modified by incorporating alkyl-groups. ${ }^{16}$ Addition of the methyl groups in the silica structure was carried out by reaction of the precursor tetraethylorthosilicate (TEOS) with methyltriethoxysilane (MTES) as shown in Figure 3. After coating the porous intermediate layer with the MTES modified polymer silica sol, the membranes were heated in air at $250^{\circ} \mathrm{C}$. The pore size of the membranes was assessed by single gas permeation measurements (GPM) with various gases with increased kinetic diameter, that is, $\mathrm{He}, \mathrm{H}_{2}, \mathrm{CO}_{2}, \mathrm{~N}_{2}$ and $\mathrm{CH}_{4}$. The GPM indicates that the pores of the methylated silica membrane (MSM) are larger than those in the $\mathrm{SiO}_{2}$ membranes, but smaller than 1 nm.

In this research, results obtained with both silica and methylated silica membranes are presented. The silica membrane (silica1) was tested at low-pressure (up to 10 bar) while the methylated silica membrane (silica2) was tested at higher pressure (15-30 bar).

\section{Apparatus and Experimental Procedure}

Two different apparatus were used for membrane performance tests, one at Bath, the other at ECN. All flow rates reported are at normal conditions of temperature and pressure. The apparatus at Bath, shown in Figure 4, was designed to be operated with zeolite membranes at pressures up to 100 bar. In this particular study, the experiments were performed at feed pressures up to 10 bar only, and temperatures between 25 to $100^{\circ} \mathrm{C}$. Protective pressure relief valves were connected to the main central vent system. The membrane module was constructed from stainless steel tube of $25.4 \mathrm{~mm}$ o.d for tubular

Table 1. Summary of the Properties of the Support and Silica Membrane Layer

\begin{tabular}{clllcc}
\hline Layer & Coating Type & \multicolumn{1}{c}{ Name } & Compound & Thickness \\
\hline 1 & Suspension & Extruded tube & $\alpha-\mathrm{Al}_{2} \mathrm{O}_{3}$ & $3000 \mu \mathrm{m}$ & Porosity \\
2 & Suspension & Alpha 1 & $\alpha-\mathrm{Al}_{2} \mathrm{O}_{3}$ & $30-50 \mu \mathrm{m}$ & 0.35 \\
3 & Sol-gel & Gamma & $\alpha-\mathrm{Al}_{2} \mathrm{O}_{3}$ & $30-40 \mu \mathrm{m}$ & 0.22 \\
4 & Sol-gel & Silica & $\gamma-\mathrm{Al}_{2} \mathrm{O}_{3}$ & $1.5-2.0 \mu \mathrm{m}$ & 0.34 \\
5 & $\mathrm{SiO}_{2}$ & $50-180 \mathrm{~nm}$ & 0.5 \\
\hline
\end{tabular}




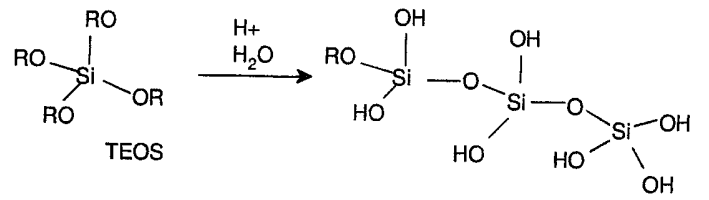

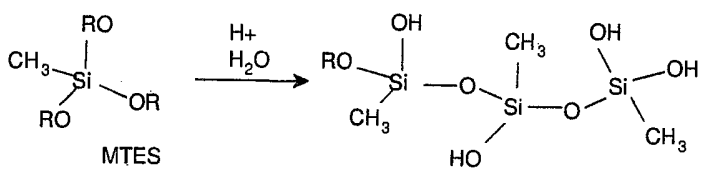

Figure 3. Simplified reaction scheme for silica and modified silica membranes.

membranes and $20 \mathrm{~mm}$ for fiber membranes. The module was provided by Pall-Exekia.

The test gas (or gas mixture) from the make-up cylinder was introduced via a pressure regulator, a mass flow controller, and a three-way valve into the membrane module. The temperature of the module was regulated by placing it in a temperature controlled water bath or a heating cabinet. The experiments were run until steady state was attained. The pressures on both the feed and permeate sides were controlled using backpressure regulators, and the pressures in both these streams and the retentate were recorded using digital pressure transducers. Gas flow rates at the inlets were measured using the mass flow controllers, which were regularly calibrated using bubble flow meters. At the outlets, the retentate and permeate flow rates were measured using bubble flow meters. A PerkinElmer GC, connected to the rig through a stream selection valve, was used for on-line analysis of the gas compositions of all four streams. The feed flow rate used was in the range $100-1,800 \mathrm{~mL}$. $\min ^{-1}$. The sweep gas on the permeate side was nitrogen with a flow rate in the range $10-1,000 \mathrm{~mL} \mathrm{~min}^{-1}$. The membrane module was operated in countercurrent mode. The pressure drop along the module on both sides was relatively small at 5 $\mathrm{kPa}$.

A high-pressure, high-temperature facility for testing silica membranes under realistic process conditions (feed

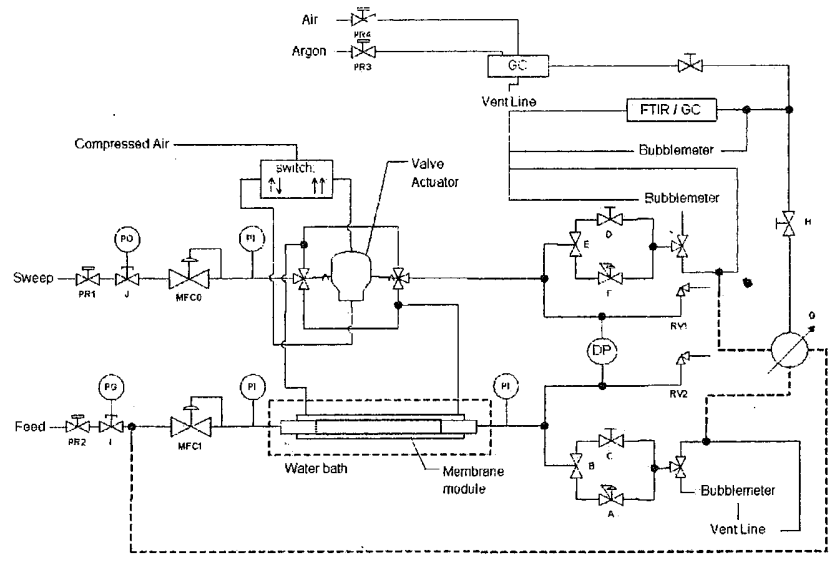

Figure 4. Experimental apparatus.

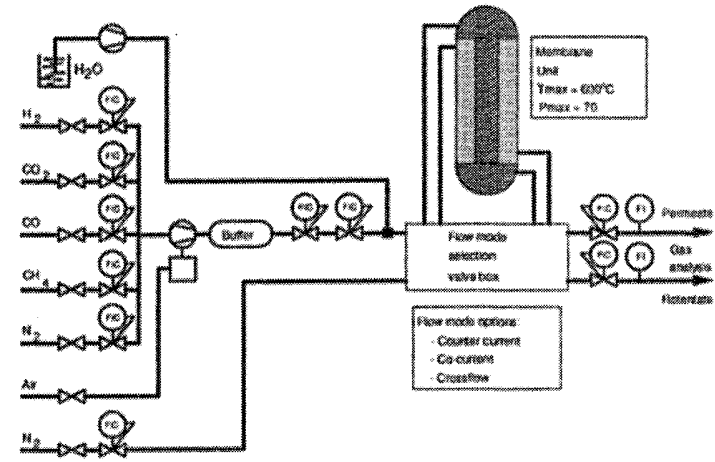

Figure 5. Simplified flow sheet of the high-pressure gas separation equipment used by ECN for silica membrane testing.

pressures up to $70 \mathrm{bar}$, temperatures up to $600^{\circ} \mathrm{C}$ ) has been used additionally for ammonia separation tests at ECN. A simplified flow sheet of the installation is shown in Figure 5. The apparatus was designed to provide high feed flows and gas mixtures without trace contaminants. To obtain the high-flow rates at high-pressure this equipment has a built-in mixing facility. Almost any mixture can be obtained by adjusting the flow ratio of the pure gases $\left(\mathrm{H}_{2}, \mathrm{CO}_{2}, \mathrm{CO}\right.$, $\mathrm{CH}_{4}, \mathrm{~N}_{2}, \mathrm{NH}_{3}$ ) through the mass flow controllers (MFC). The gases, delivered to the installation at a pressure of approximately 5 bar, are compressed by a booster to a maximum pressure of 70 bar and are stored (temporarily) in a small storage drum $(5 \mathrm{~L})$. The drum is emptied through a pressure controller, which determines the feed pressure to a MFC. This MFC sets the feed flow to the membrane, which is mainly limited by the capacity of the booster. A typical value for the flow of the chosen booster at high-pressure is $15 \mathrm{~L}$. $\min ^{-1}$, and at moderate pressures the maximum flow is $27 \mathrm{~L}$. $\min ^{-1}$. Feed and sweep gas can be heated and are fed to the membrane module. When necessary water can be added to the feed stream. The module is placed in an oven that can be heated to a maximum temperature of $600^{\circ} \mathrm{C}$. After the membrane, the retentate and permeate pressures are decreased to atmospheric pressure and the flows in both streams are measured using flow indicators. Finally, the gas flows to an Agilent micro GC in which compositions can be determined.

\section{Theoretical background}

The selectivity was calculated from the experimental data by two methods. In the first, the selectivity between two components " $i$ " and " $j$ " is set equal to the ratio of the mole fraction between the feed and the permeate. This method takes into account the mole fractions of a component in two (feed and permeate) of the four gas streams only, and it is not the most representative value when the concentration on one side of the membrane varies greatly between the inlet and the outlet of the module. 


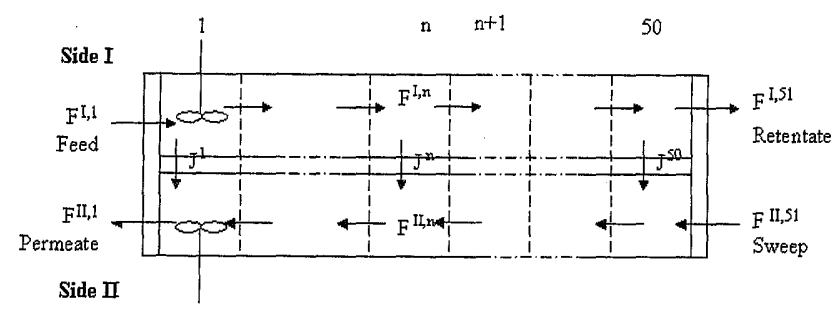

Figure 6. Membrane configuration for the improved model.

$$
S_{f i j}=\frac{\left(x_{\text {perm }} / x_{\text {feed }}\right)_{i}}{\left(x_{\text {perm }} / x_{\text {feed }}\right)_{j}}
$$

In the second method, the intrinsic selectivity between " $i$ " and " $j$ " is set to be the ratio of the permeances

$$
\alpha_{i j j}=\frac{\text { Permeance }_{i}}{\text { Permeance }_{j}}
$$

Two methods are commonly used to calculate the permeances, namely the well-mixed model and the log-mean pressure difference (LMPD) model.

\section{Well-mixed model}

The simplest method is to consider the system to be well mixed on both sides of the membrane. ${ }^{27,28}$ The permeance is then estimated from the flux through the membrane as follows

$$
J_{i}=A \frac{\bar{P}_{i}}{l} \cdot\left(p_{i}^{r e t}-p_{i}^{\text {perm }}\right)=\left(x_{i} Q\right)_{p e r m}
$$

This model is valid if the membrane operates in differential mode, that is, when there is no significant concentration gradient along the membrane surface in the axial direction. The method therefore is most suited when very small concentration changes might occur, for example, at short membrane length, low fluxes through the membrane or high-feed flows.

\section{Log-mean pressure difference (LMPD)}

The partial pressure analogy to the "log mean" temperature approach for heat exchanger performance is considered to overcome the limitation of the well-mixed model. ${ }^{29}$ This model makes some allowance for concentration gradients along the membrane without requiring a full integral solution

$$
J_{i}=A \frac{\bar{P}_{i}}{l} \cdot \frac{\left(\Delta P_{i}^{1}-\Delta P_{i}^{0}\right)}{\ln \left(\frac{\Delta P_{i}^{1}}{\Delta P_{i}^{0}}\right)}=\left(x_{i} Q\right)_{p e r m}
$$

\section{Improved model}

Both the well-mixed and log mean approaches have limitations. The well-mixed system requires the concentrations to stay relatively constant between the inlets and the outlets. By analogy with the heat exchanger in which the log-mean driving force method is only applicable if the overall heat-transfer coefficient remains virtually constant, the overall mass-transfer coefficient should accordingly remain constant. However, the experimental results shown later reveal that the fluxes vary significantly along the membrane, thereby invalidating this assumption.

To overcome these limitations, an improved model has been used in which the membrane is considered to be a series of small mixed chambers as shown in Figure 6. This segmental approach to modeling membrane design and performance has been described previously by McCabe et al. ${ }^{30}$. In this model $\mathrm{F}^{\mathrm{n}}$ is the total molar flow along the $\mathrm{n}^{\text {th }}$ segment of the membrane, and $\mathrm{J}^{\mathrm{n}}$ is the total flux across the membrane in that segment. If the number of mixed chambers is high enough the variation in concentration in each chamber should be negligible allowing the equations for the well-mixed model to be used in each of them.

The system of equations to be solved is based on the wellmixed system applied to a volume element $n$ of surface area $A_{n}$. The flux across the membrane for each component " $i$ " is determined by

$$
J_{i}^{n}=A_{n} \frac{\bar{P}_{i}}{l}\left(p_{i}^{I, n}-p_{i}^{I I, n}\right)
$$

The permeances $\vec{P}_{i} / l$ are considered to be constant along the membrane. The transmembrane fluxes $J_{i}^{n}$ are used to determine the flow rates for the next volume element by

$$
J_{i}^{n}=F_{i}^{I, n+1}-F_{i}^{I, n}=F_{i}^{I I, n+1}-F_{i}^{I I, n}
$$

It is then possible to estimate the mole fraction of each component on both sides of the membrane, and then their partial pressures

$$
x_{i}^{I, n+1}=\frac{F_{i}^{I, n+1}}{F^{I, n+1}}=\frac{p_{i}^{I, n+1}}{p^{I, n+1}}
$$

\begin{tabular}{|c|c|c|c|c|c|}
\hline \multirow[b]{2}{*}{ Membrane } & \multicolumn{3}{|c|}{ Permeances (mol.m $\left.\mathrm{m}^{-2} \cdot \mathrm{s}^{-1} \cdot \mathrm{Pa}^{-1}\right)$} & \multirow[b]{2}{*}{$\alpha_{\mathrm{NH} 3 / \mathrm{H} 2}$} & \multirow[b]{2}{*}{$\alpha_{\mathrm{NH} 3 / \mathrm{N} 2}$} \\
\hline & $\mathrm{NH}_{3}$ & $\mathrm{H}_{2}$ & $\mathrm{~N}_{2}$ & & \\
\hline Tube (zeolite2) & $2.14 \times 10^{-7}$ & $2.34 \times 10^{-8}$ & $1.52 \times 10^{-8}$ & 9.13 & 14.09 \\
\hline Fibre (zeolite) & $1.30 \times 10^{-8}$ & $1.82 \times 10^{-9}$ & $6.29 \times 10^{-10}$ & 7.14 & 20.66 \\
\hline Tube (silica2) & $7.62 \times 10^{-7}$ & $1.15 \times 10^{-7}$ & $5.26 \times 10^{-8}$ & 6.60 & 14.48 \\
\hline
\end{tabular}

With these partial pressures, the transmembrane fluxes can be estimated for the next volume element $\mathrm{n}+1$ with $A_{n+1}=A_{n}=A$ / (number of elements). This process is repeated along the membrane starting from the feed/permeate end to the sweep/retentate end as follows

Table 2. Gas Separation Experiments Performed on Three Types of Membranes 
Table 4. Experiments Performed on the Membrane Zeolite2 at $25^{\circ} \mathrm{C}, \mathrm{P}_{\text {sweep }}=1 \mathrm{bar}, \mathrm{F}_{\text {feed }}=200 \mathrm{ml} / \mathrm{min}, \mathrm{F}_{\text {sweep }}=15 \mathrm{ml} / \mathrm{min}$

\begin{tabular}{|c|c|c|c|c|c|c|}
\hline \multirow{2}{*}{$\begin{array}{c}P_{\text {feed }} \\
\text { bar }\end{array}$} & \multirow[b]{2}{*}{$\mathrm{NH}_{3}$ Feed } & \multicolumn{3}{|c|}{ Permeances $\left(\mathrm{mol} \cdot \mathrm{m}^{-2} \cdot \mathrm{s}^{-1} \cdot \mathrm{Pa}^{-1}\right)$} & \multicolumn{2}{|c|}{ Separation factors } \\
\hline & & $\mathrm{N}_{2}$ & $\mathrm{H}_{2}$ & $\mathrm{NH}_{3}$ & $\alpha \mathrm{NH}_{3} / \mathrm{N}_{2}$ & $\alpha \mathrm{NH}_{3} / \mathrm{H}_{2}$ \\
\hline 10.0 & $16 \%$ & $1.94 \times 10^{-8}$ & $2.14 \times 10^{-8}$ & $6.00 \times 10^{-8}$ & 3.10 & 2.80 \\
\hline 10.0 & $9 \%$ & $2.24 \times 10^{-8}$ & $2.07 \times 10^{-8}$ & $6.40 \times 10^{-8}$ & 2.84 & 3.08 \\
\hline 10.0 & $2 \%$ & $2.00 \times 10^{-8}$ & $1.84 \times 10^{-8}$ & $9.19 \times 10^{-7}$ & 4.61 & 5.00 \\
\hline
\end{tabular}

The sweep was composed of pure nitrogen.

ential pressure was applied to the membrane, the selectivity decreased. This may be due to an extra flow through the larger pores or defects created by a higher differential pressure. Furthermore, additional gas may permeate through due to the opening of the pores in which the ammonia is already condensed.

Different feed concentrations have been studied with the zeolite tubular membrane zeolite 2 at $25^{\circ} \mathrm{C}$ and the results are presented in Table 4 . The permeance of ammonia was increased significantly when the amount of ammonia in the feed was reduced. It seems that the ammonia is completely saturating the zeolite pores when it reaches a partial pressure of around 1 bar, leading to a change in governing transport mechanism. This can explain the relatively small variations in performance observed with ammonia concentrations in the feed of 16 and 9\% (that is, an ammonia partial pressure of 1.6 and 0.9 bar, respectively). Accordingly, most of the experiments were performed with ammonia feed concentrations of $9 \%$. With a feed of $2 \%$ ammonia and a feed pressure of 10 bar $(0.2$ bar of ammonia partial pressure), the zeolite membrane may not be saturated with ammonia allowing an easier passage of ammonia across the membrane. Interestingly, this variation in feed concentration has no major influence on the permeances of hydrogen and nitrogen.

For a nonmethylated silica membrane (silica1) with the same experimental conditions as in Table 4 , but with an $18 \%$ ammonia feed composition and without any sweep gas, much lower permeances and selectivities were observed (Permeances in mol.m ${ }^{-2} \cdot \mathrm{s}^{-1} \cdot \mathrm{Pa}^{-1}: \mathrm{N}_{2}=5.94 \times 10^{-9}, \mathrm{H}_{2}=7.75 \times 10^{-9}$, $\left.\mathrm{NH}_{3}=9.92 \times 10^{-9}, \alpha \mathrm{NH}_{3} / \mathrm{N}_{2}=1.67, \alpha \mathrm{NH}_{3} / \mathrm{H}_{2}=1.28\right)$. These results confirm that for the $\mathrm{NH}_{3} / \mathrm{H}_{2} / \mathrm{N}_{2}$ separation, the performance of a methylated silica membrane is better than the standard silica one.

Figures $9 \mathrm{a}$ and $\mathrm{b}$ show the effect of temperature on the ammonia and hydrogen permeances obtained for gas separation experiments between 40 and $100^{\circ} \mathrm{C}$ for tubular and fiber MFI zeolite membranes and between 20 and $200^{\circ} \mathrm{C}$ for the silica membrane (silica1) without any sweep gas. For the zeolite membranes, the permeances obtained with the fiber geometry are about 10 times lower than those obtained with the tubular geometry due to the higher thickness of the membrane layer in the former. However, the fibers showed much higher separation factors $\left(\alpha \mathrm{NH}_{3} / \mathrm{H}_{2}=16\right)$ compared to 8 and 6 for tubular zeolite and silica membranes. For the tubular silica membrane (silica1) the maximum ammonia permeance $\left(5.8 \times 10^{-8}\right.$ mol. $\mathrm{m}^{-2} \cdot \mathrm{s}^{-1} \cdot \mathrm{Pa}^{-1}$ ) was obtained at $80^{\circ} \mathrm{C}$, this temperature also providing the maximum ammonia permeance for the tubular zeolite membrane. This effect has already been observed by Kumakiri et al..$^{34}$ at low-pressure. The trend observed in Figure $9 \mathrm{a}$ for the tubular ceramic membranes is the combined effect of strong adsorption at lower temperature, and increased diffusion at higher temperature. The ammonia permeance for the fiber membrane virtually remained constant across the temperature range while the hydrogen permeance increased, thereby leading to a better separation factor for the fiber membrane at low-temperature. The effect of temperature on the gas permeances in the fiber is much attenuated, considering the thickness of the separating material. As for ammonia the increase in temperature would increase the diffusion of hydrogen across the membrane, thereby increasing its permeance as shown in Figure $9 b$.

\section{Modeling}

The experimental results were analyzed using the three models, the permeances being shown in Table 5. It can be seen that, because of the high concentration of hydrogen $(>60 \%)$ in the system, and the small changes in hydrogen concentrations on both sides of the membrane, all three models give similar values for the permeance of hydrogen. Due to the large variation in the partial pressure of ammonia along the tubular membrane, the well-mixed model is not able to provide a meaningful value for the permeance. The LMPD model only uses the inlet and outlet concentrations, but provides permeances that are much more in-line with those obtained from the improved model in which much better account is taken of the concentration change along the membrane. With the zeolite fiber membrane, the ammonia flux was found to be lower than for the tube or silica membrane, thereby giving a smaller concentration change along the membrane. Here the wellmixed model is in much better agreement with the improved model. For the high-concentration variations obtained with the methylated silica membrane, the observations compare well with those for the tubular zeolite membrane. However, for a
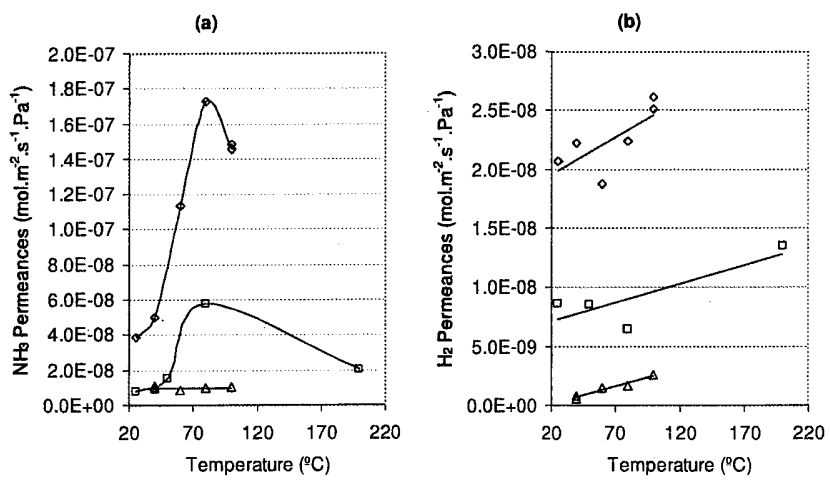

Figure 9. Effect of temperature on the permeances of ammonia (a), and hydrogen (b) obtained with the tubular zeolite (zeolite1) $(\diamond)$, fiber zeolite $(\triangle)$ and tubular silica (silica1) $(\square)$ membranes.

2062 DOI 10.1002/aic Published on behalf of the AIChE June 2006 Vol. 52, No. $6 \quad$ AIChE Journal 
Table 5. Comparison of the Results Obtained from Three Models for Tube and Fiber Zeolite Membranes and Methylated Silica Membranes

\begin{tabular}{|c|c|c|c|c|c|c|c|c|}
\hline \multirow{2}{*}{$\begin{array}{c}\text { Membrane } \\
\text { Type }\end{array}$} & \multirow{2}{*}{$\begin{array}{c}\mathrm{x}_{\mathrm{NH}}^{\mathrm{feed}} \\
\%\end{array}$} & \multirow{2}{*}{$\begin{array}{c}\mathrm{X}_{\mathrm{NH}_{3}}^{\text {retentate }} \\
\%\end{array}$} & \multicolumn{2}{|c|}{ Permeances (well mixed) } & \multicolumn{2}{|c|}{ Permeances (LMPD) } & \multicolumn{2}{|c|}{ Permeances (improved) } \\
\hline & & & $\mathrm{H}_{2}$ & $\mathrm{NH}_{3}$ & $\mathrm{H}_{2}$ & $\mathrm{NH}_{3}$ & $\mathrm{H}_{2}$ & $\mathrm{NH}_{3}$ \\
\hline Tube & 9.00 & 1.73 & $1.99 \times 10^{-8}$ & $-2.00 \times 10^{-6}$ & $1.97 \times 10^{-8}$ & $1.55 \times 10^{-7}$ & $2.18 \times 10^{-8}$ & $1.34 \times 10^{-7}$ \\
\hline Tube & 9.00 & 1.12 & $2.04 \times 10^{-8}$ & $1.25 \times 10^{-4}$ & $2.07 \times 10^{-8}$ & $2.07 \times 10^{-7}$ & $2.27 \times 10^{-8}$ & $2.00 \times 10^{-7}$ \\
\hline Fibre & 9.00 & 8.92 & $1.64 \times 10^{-9}$ & $1.30 \times 10^{-8}$ & $1.65 \times 10^{-9}$ & $1.15 \times 10^{-8}$ & $1.82 \times 10^{-9}$ & $1.30 \times 10^{-8}$ \\
\hline Fibre & 9.00 & 8.34 & $1.37 \times 10^{-9}$ & $1.23 \times 10^{-8}$ & $1.38 \times 10^{-9}$ & $9.90 \times 10^{-9}$ & $1.52 \times 10^{-9}$ & $1.09 \times 10^{-8}$ \\
\hline MSM Silica & 14.8 & 9.66 & $1.13 \times 10^{-7}$ & $1.33 \times 10^{-6}$ & $1.13 \times 10^{-7}$ & $7.62 \times 10^{-7}$ & $1.15 \times 10^{-7}$ & $7.62 \times 10^{-7}$ \\
\hline MSM Silica & 14.7 & 13.2 & $7.14 \times 10^{-8}$ & $2.57 \times 10^{-7}$ & $5.86 \times 10^{-8}$ & $1.38 \times 10^{-7}$ & $6.27 \times 10^{-8}$ & $1.72 \times 10^{-7}$ \\
\hline
\end{tabular}

smaller concentration variation the ammonia permeance obtained with the improved model was found to be between the LMPD and well-mixed values.

The experimental data for the tube (zeolite 2) given in Table 2 were used to generate the flow patterns along the membrane with the improved model. Figures 10 and 11 clearly show that the individual gas flows and the total flux change significantly along the membrane on the retentate and on the permeate sides, respectively. Hence, as explained previously the LMPD model may not be the most suitable model for this system.

Figure 12 shows simulated results of the ammonia-hydrogen selectivity $\left(S_{f}\right)$ vs. the feed flow rate along the tubular zeolite membrane using the improved model. The feed was composed of $9 \% \mathrm{NH}_{3}$, and a $3: 1 \mathrm{H}_{2} / \mathrm{N}_{2}$ ratio. These results were obtained by setting the permeances of ammonia and hydrogen to be $2.14 \times 10^{-7}$, and $2.34 \times 10^{-8} \mathrm{~mol} \cdot \mathrm{m}^{-2} \cdot \mathrm{s}^{-1} \cdot \mathrm{Pa}^{-1}$, respectively. The intrinsic selectivity $(\alpha)$ is then 9.13. The experimental feed pressure of 10 bar and sweep pressure of 1 bar for these permeances were used for the simulations.

Curve (e) clearly shows that at the lowest feed flow rate the selectivity decreases rapidly from two to almost zero due to the depletion of ammonia in the retentate. Only about $50 \%$ of the membrane area is gainfully used. As the feed flow rate is increased to $202 \mathrm{~mL} \cdot \mathrm{min}^{-1}$ the selectivity improves to around 7.5 , approaching the intrinsic value. The predictions indicate that the ammonia partial pressure along the membrane influences the transport across it.

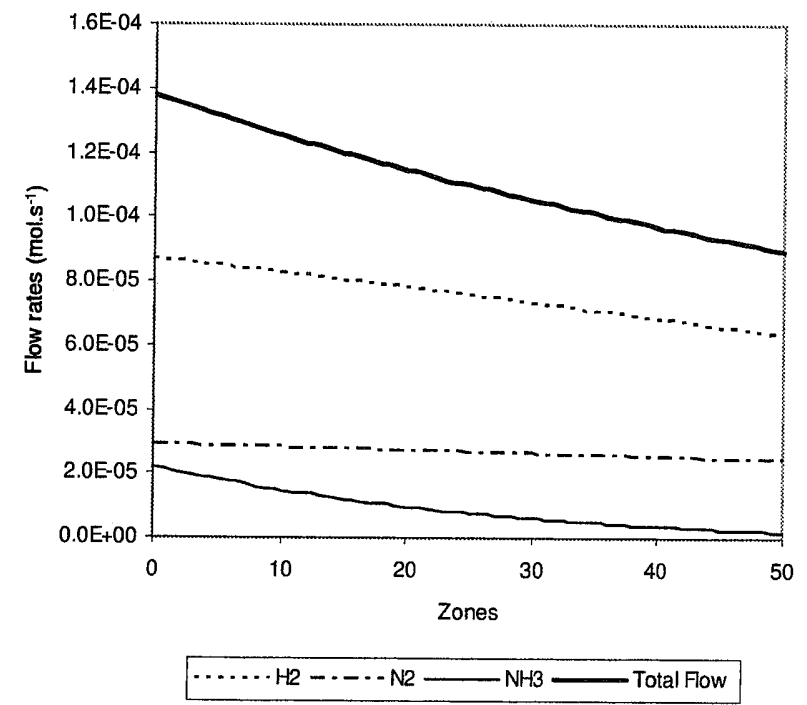

Figure 10. Flow changes along the membrane on the retentate side under experimental conditions.

\section{Industrial case study}

For an industrial process it is necessary to determine the surface area required to reduce the concentration of ammonia in the retentate to an amount of typically $2 \%$, in the syngas loop. The improved model can be used iteratively to solve this problem if the permeances of the components are known. In this simulation, the surface area of each mixed chamber is fixed, and the number of chambers required to reduce the ammonia retentate concentration to the desired amount is determined by the iterative process. The required surface areas for an industrial ammonia separation were calculated for tubular and fiber zeolite membranes, and for the methylated silica membranes using the improved model. The industrial conditions used for the simulation are feed composition of $16 \%$ ammonia, 21\% nitrogen and $63 \%$ hydrogen and a sweep composition of 3:1 $\mathrm{H}_{2} / \mathrm{N}_{2}$. The feed and sweep pressures are set to 115 and 26.5 bar, respectively and feed and sweep flow rates of 7091 and 1557 mol.s ${ }^{-1}$ have been used. The permeances used for the simulations are those given in Table 2. The model indicates that the higher the permeance of ammonia for a given membrane, the lower the membrane area required for such a process to be more cost-effective. The areas required to reduce the feed concentration to the desired $2 \%$ with the methylated silica, zeolite and fiber membranes were 2286, 8484 and $136512 \mathrm{~m}^{2}$, respectively.

With the improved model, it is possible to examine the impact of some of the design and process parameters, such as the permeances of components or the feed and sweep flow rates

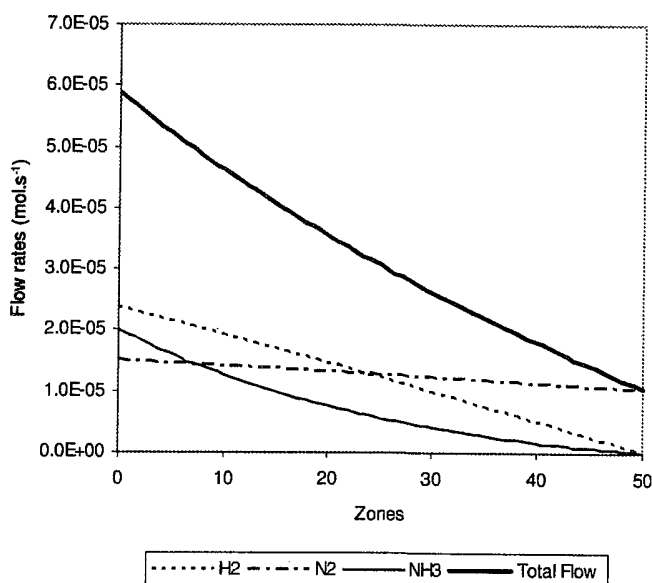

Figure 11. Flow changes along the membrane on the permeate side under experimental conditions. 


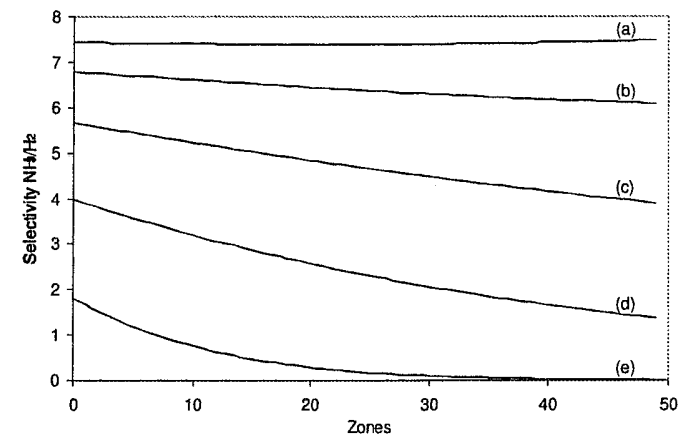

Figure 12. Predicting the effect of feed flow on selectivity along the membrane obtained with the improved model: (a) $202 \mathrm{~mL} / \mathrm{min}$, (b) $100 \mathrm{~mL} /$ min, (c) $50 \mathrm{~mL} / \mathrm{min}$, (d) $25 \mathrm{~mL} / \mathrm{min}$, (e) $10 \mathrm{~mL} /$ $\min$.

or pressures on the required surface area. Figure 13 shows, for example, the influence of the ammonia-hydrogen selectivity on the surface area for four different values of the permeance of hydrogen. For ease of demonstration of results in this scenario, the permeance of nitrogen is chosen to be equal to that of hydrogen. The pressures, flow rates and inlet compositions are indicated in the figure.

For a fixed value of the permeance of hydrogen, an increase in the selectivity decreases the surface area required to reach the desired $2 \%$ of ammonia in the retentate as the $\mathrm{NH}_{3}$ permeance increases. Furthermore, the model shows that for a fixed value of the permeance of ammonia, the surface area required is smaller with a smaller selectivity. Indeed, with a small selectivity of $\mathrm{NH}_{3} / \mathrm{H}_{2}$, more $\mathrm{H}_{2}$ and $\mathrm{N}_{2}$ passes through the membrane reducing significantly $\mathrm{NH}_{3}$ partial pressure on the sweep side, and thereby increasing the ammonia flux. The hydrogen and nitrogen in the permeate can be recycled in the process and can be recompressed. It is then necessary to find a

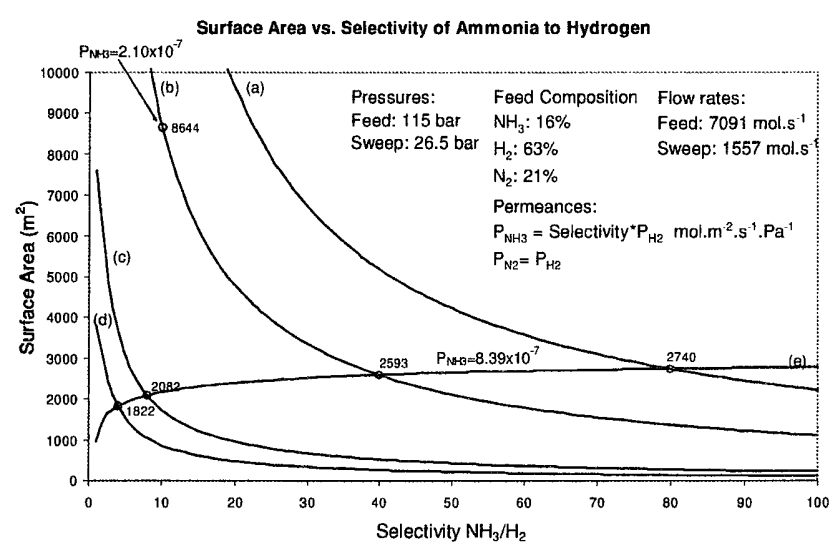

Figure 13. Evolution of the required surface area in relation to the ammonia-hydrogen selectivity for four values of the permeance of hydrogen: (a) $1.05 \times 10^{-8}$, (b) $2.10 \times 10^{-8}$, (c) $1.05 \times$ $10^{-7}$, (d) $2.10 \times 10^{-7} \mathrm{~mol}_{\mathrm{m}} \mathrm{m}^{-2} \mathrm{~s}^{-1} \cdot \mathrm{Pa}^{-1}$, and one value of the permeance of ammonia e) $8.39 \times 10^{-7}$ mol.m $\mathrm{m}^{-2} \cdot \mathrm{s}^{-1} \cdot \mathrm{Pa}^{-1}$. compromise in profitability between reducing the surface area of the membrane or reducing the size of the compressor.

\section{Conclusions}

An extensive zeolite and silica membrane screening program has been performed on the ammonia/hydrogen/nitrogen system. A high ammonia permeance of $2.1 \times 10^{-7}$ mol. $\mathrm{m}^{-2} \cdot \mathrm{s}^{-1} \cdot \mathrm{Pa}^{-1}$, and a selectivity of about 10 were obtained with a tubular MFI zeolite membrane at $80^{\circ} \mathrm{C}$. While for the methylated silica membrane the ammonia permeance was found to be higher than for the zeolite, the corresponding selectivity was lower (7). The zeolite fiber membrane tested also showed a high selectivity of about 15 at $40^{\circ} \mathrm{C}$, but the permeances obtained were lower than those with the tubular membrane. The tubular membrane could be used for highpressure industrial applications, while the fibers could be used in applications where lower fluxes are acceptable. A segmental model has been used for data analysis, process design and simulation. This improved model takes into account concentration changes along both sides of the membrane. Accordingly, this model gives the best representation of the behavior of the membrane for all experimental conditions. This model can also be used to predict the membrane area required for particular industrial applications when the permeances of the three gases are available from laboratory experiments. In an industrial application, the variations in concentrations and membrane fluxes in the direction along the membrane are important parameters in design and analysis. The well-mixed and $\log$ mean pressure difference models cannot properly account for these important variations, and, hence, the improved model ought to be considered more seriously by the practicing engineer.

\section{Acknowledgments}

The authors are grateful to the European Commission for financial support of this work in the IMPRESS project (Project GIRD-CT 199900078).

\section{Notation}

$$
\begin{aligned}
A= & \text { total membrane surface area } \\
A_{n}= & \text { membrane surface area of a volume element } \mathrm{n} \\
d p= & \text { pore dia. } \\
F^{I, n}= & \text { total flow rate on the feed/retentate side entering a } \\
& \text { volume element } \mathrm{n} \\
F^{I, 1}= & \text { total feed flow rate } \\
F^{I, 51}= & \text { total retentate flow rate } \\
F_{i}^{I, n}= & \text { flow rate of component "i" on the feed/retentate } \\
& \text { side entering a volume element } \mathrm{n} \\
F^{I, n}= & \text { total flow rate on the sweep/permeate side entering } \\
& \text { a volume element } \mathrm{n} \\
F^{I I, 1}= & \text { total permeate flow rate } \\
F^{I I, 51}= & \text { total sweep flow rate } \\
F_{i}^{I I, n}= & \text { flow rate of component " } \mathrm{i} \text { " on the sweep/permeate } \\
& \text { side entering a volume element } \mathrm{n} \\
J_{i}= & \text { flux of component " } \mathrm{i} \text { " across the membrane } \\
J^{n}= & \text { total flux across the membrane at the volume } \\
& \text { element } \mathrm{n} \\
J_{i}^{m}= & \text { flux of component "i" across the membrane for a } \\
& \text { volume element } \mathrm{n} \\
l= & \text { thickness of the membrane } \\
\bar{P}_{i}= & \text { permeability of component " } \mathrm{i} \text { " } \\
P_{i}^{r e t}= & \text { partial pressure of component "i" in the retentate } \\
p_{i}^{f e e d}= & \text { partial pressure of component "i" in the feed } \\
P_{i}^{p e r m}= & \text { partial pressure of component "i" in the permeate }
\end{aligned}
$$

June 2006 Vol. 52, No. 6

AIChE Journal

AIChE Journal 


$$
\begin{aligned}
& p_{i}^{\text {sweep }}=\text { partial pressure of component " } \mathrm{i} \text { " in the sweep } \\
& p_{i}^{l, n}=\text { partial pressure of component " } \mathrm{i} \text { " on the feed } /
\end{aligned}
$$

\section{Subscript}

$i=$ represents the component "i" of the gas mixture $\left(\mathrm{NH}_{3}, \mathrm{H}_{2}\right.$ or $\left.\mathrm{N}_{2}\right)$

\section{Literature Cited}

1. Molinari R, Gagliardi R, Drioli E. Methodology for estimating saving of primary energy with membrane operations in industrial processes. Desalination. 1995;100;125-137.

2. Stephan W, Noble RD, Koval CA. Design methodology for a membrane/distillation column hybrid process. I of Membr Sci. 1995;99: 259-272.

3. Sommer $S$. Transport of $\mathrm{C}_{6}$ isomers through ZSM-5 zeolite membranes. $J$ of Membr Sci. 2003;224:51-54.

4. De Vos RM, Nijmeijer A, Keizer K, Verweij H. The preparation and analysis of microporous silica membranes for gas separation. Special Publication - Royal Society of Chemistry. 1997;213(Characterisation of Porous Solids IV):675-680.

5. Piera E, Giroir-Fendler A, Dalmon J-A, Moueddeb H, Coronas J, Menendez M, Santamaria J. Separation of alcohols and alcohols $/ \mathrm{O}_{2}$ mixtures using zeolite MFI membranes. $J$ of Membr Sci. 1998;142: 97-109.

6. Hyun SH, Song JK, Kwak BI, Kim JH, Hong SA. Synthesis of ZSM-5 zeolite composite membranes for CO_2 separation. $J$ of Mat Sci. 1999;34(13):3095-3103.

7. van de Graaf JM, van der Bijl E, Stol A, Kapteijn F, Moulijn JA. Effect of operating conditions and membrane quality on the separation performance of composite silicalite-1 membranes. Ind \& Eng Chem Res. 1998;37:4071-4083.

8. Kusakabe K, Kuroda T, Uchino K, Hasegawa Y, Morooka S. Gas permeation properties of ion-exchanged faujasite-type zeolite membranes. AIChE J. 1999;45:1220-1226.

9. Kusakabe K, Murata A, Kuroda T, Morooka S. Preparation of MFItype zeolite membranes and their use in separating n-butane and i-butane. $J$ of Chem Eng of J. 1997;30:72-78.

10. Lai R, Gavalas GR. ZSM-5 membrane synthesiswith organic-free mixtures. Microporous and Mesoporous Mat. 2000;38:239-245.

11. Yan Y, Davis ME, Gavalas GR. Preparation of highly selective zeolite ZSM-5 membranes by a post-synthetic coking treatment. $J$ of $\mathrm{Membr}$ Sci. 1997;123:95-103.

12. Uhlhorn RJR, Huis In't Veld MHBJ, Keizer K, Burggraaf AJ. High permselectivities of microporous silica-modified $\gamma$-alumina membranes. J of Materials Sci Letts. 1989;8:1135-1138.
13. De Vos RM, Verweij H. Improved performance of silica membranes for gas separation. J of Membr Sci. 1998;143:37-51

14. Gomes D, Nunes SP, Peinemann KV. Membranes for gas separation based on poly(1-trimethylsilyl-1-propyne)-silica nanocomposites. $J$ of Membr Sci. 2005;246:13-25

15. Fotou GP, Lin YS, Pratsinis SE. Hydrothermal stability of pure and modified microporous silica membranes. J of Material Sci. 1995;30: 2803-8.

16. De Vos RM, Verweij H, Bonekamp BC, Pex PPAC. Process of producing a microporous hydrophobic inorganic membrane. WO99/ 61140. 1999.

17. Campaniello J, Engelen CWR, Haije WG, Pex PPAC, Vente JF. Long-term pervaporation performance of microporous methylated silica membranes. Chem. Commun. Febr. 2004:834-835.

18. Kerkhof PJAM. Partial analytical solutions for steady-state diffusion in zeolite membranes. AIChE J. 1998;44:1697-1700.

19. Krishna R, van den Broeke LJP. The Maxwell-Stefan description of mass transport across zeolite membranes. Chem Eng and Biochem Eng J. 1995;57:155-162.

20. Marriott JI, Sorensen E, Bogle IDL. Detailed mathematical modelling of membrane modules. Comp and Chem Eng. 2001;25:693-700.

21. Soria R. Overview on industrial membranes. Catalysis Today. 1995; 25:285-290.

22. Ramsay J, Giroir-Fendler A, Julbe A, Dalmon J-A. Materiau inorganique poreux, notament sous forme de membrane, et procede d'obtention d'un tel materiau. French Patent 9405 562. 1994.

23. Yang M, Crittenden BD, Perera SP, Mouedded H, Dalmon J-A. The hindering effect of strongly adsorbed components on the permeation of a weakly absorbed component through a microporous silicalite membrane: the potential barrier theory. $J$ of Membr Sci. 1998;156:1-9.

24. Societe des Ceramiques Techniques, Soria R, Cayrey J-M, Foulon J-C, Homogeneous massive porous ceramic material. World patent application WO9948840. 1999-09-30. 1999.

25. Societe des Ceramiques Techniques, Soria R, Cayrey J-M, Foulon J-C. Multichannel porous ceramic fibre. World patent application WO9948839. 1999-09-30. 1999.

26. Bonekamp BC. Preparation of asymmetric ceramic membrane supports by dip-coating. In: Burggraaf AJ, Cot L. Fundamentals of Inorganic Membrane Science and Technology. Amsterdam: Elsevier; 1996:141-226

27. Hägg M-B. Purification of chlorine gas with membranes - an integrated process solution for magnesium production. Sep Pur Technol. 2001;21:261-278

28. Weller S, Steiner WA. Engineering aspects of separation of gases. Chem Eng Progr. 1950;46:585.

29. Rao MB, Sircar S. Nanoporous carbon membranes for separation of gas mixtures by selective surface flow. J of Membr Sci. 1993;85:253264.

30. McCabe WL, Smith JC, Harriott P. Unit Operations of Chemical Engineers. $6^{\text {th }}$ ed. Boston; London: McGraw-Hill; 2001.

31. Bakker WJW, van den Broeke LJP, Kapteijin F, Moulijn JA. Temperature dependence of one-component permeation through a silicalite-1 membrane. AIChE J. 1997;43:2203-2214.

32. Cracknell RF, Nicholson D, Tennison SR, Bromhead J. Adsorption and selectivity of carbon dioxide with methane and nitrogen in slitshaped carbonaceous micropores: simulation and experiment. Adsorption. 1996;2:193-203

33. Nicholson D, Gubbins KE. Separation of carbon dioxide - methane mixtures by adsorption: effects of geometry and energetics on selectivity. $J$ of Chem Physics. 1996;104:8126-8134.

34. Kumakiri I, Miachon S, Dalmon J-A. H-MFI zeolite membranes for ammonia separation. ICOM Toulouse; 2002. 2002:344.

Manuscript received Sept. 15, 2005, and revision received Jan. 19, 2006. 